\title{
Article \\ Guidelines for Teacher Training in Mobile Augmented Reality Games: Hearing the Teachers' Voices
}

\author{
Lúcia Pombo *(D) and Margarida M. Marques *(D) \\ CIDTFF- Research Centre on Didactics and Technology in the Education of Trainers, Department of Education \\ and Psychology, University of Aveiro, 3810-193 Aveiro, Portugal \\ * Correspondence: LPombo@ua.pt (L.P.); marg.marq@ua.pt (M.M.M.)
}

Citation: Pombo, L.; Marques, M.M. Guidelines for Teacher Training in Mobile Augmented Reality Games: Hearing the Teachers' Voices. Educ. Sci. 2021, 11, 597. https://doi.org/ 10.3390/educsci11100597

Academic Editor: Eila Jeronen

Received: 30 August 2021

Accepted: 27 September 2021

Published: 30 September 2021

Publisher's Note: MDPI stays neutral with regard to jurisdictional claims in published maps and institutional affiliations.

Copyright: (c) 2021 by the authors. Licensee MDPI, Basel, Switzerland. This article is an open access article distributed under the terms and conditions of the Creative Commons Attribution (CC BY) license (https:// creativecommons.org/licenses/by/ $4.0 /)$.

\begin{abstract}
Mobile augmented reality games (MARGs) can be leveraged for educational purposes, as there are several examples in the literature revealing their educational value. The supporting technologies for MARGs' implementation in education are increasingly pervasive and popular, so it is time for their adoption in teacher practices. However, the integration of new practices in schools, with an impact on students' learning, requires teacher training. For that, a $50 \mathrm{~h}$ workshop was con-ducted to promote the collaborative development of MARGs for science, technology, engineering, and mathematics learning, which was attended by 16 in-service teachers, in Portugal. The aim of this study is to propose a set of guidelines for teacher training on MARGs, emergent from the perspectives of teachers who participated in the workshop. This is a descriptive qualitative study focusing on documental analysis of the individual final reflections of the participating teachers. The results showed that the workshop answered teachers' personal and professional needs, with an impact on their practices, in what concerns the integration of mobile and AR technology, and of games. Producing a new game during training and making it freely available for others to use seemed to be very satisfactory for teachers, and a good practice to follow. From teachers' reflections, it was possible to propose a set of guidelines useful for international readership, both researchers and teacher trainers, who aim to conceive and develop continuous professional development initiatives for MARGs' integration in teacher practices.
\end{abstract}

Keywords: teacher training workshop; mobile augmented reality games; documental analysis

\section{Introduction}

Mobile augmented reality games (MARGs) are games supported by mobile devices, such as smartphones or tablets, that incorporate the presentation of interactive virtual content, such as texts, 2D or 3D graphics, audio, or even video, accurately overlaid on a real-time camera feed of the real-world environment [1]. Possibly the most acknowledged MARG worldwide is Pokémon GO, a GPS-based location game where players interact with virtual creatures that seem to be in the players' physical environment.

MARGs can be leveraged for educational purposes, as there are several examples in the literature revealing their educational value [2-4]. Among their benefits, the literature has been pointing to increased engagement and motivation for learning $[2,5,6]$ as well as students' enhanced understanding of scientific models [7] and of complex concepts that are difficult to understand with traditional textbooks [8]. For example, the authors of [9] mentioned that there is no limit to the potential valuable educational uses of AR apps that are aligned with situated [10] and constructivist learning theories [11], highlighting the relevance of social interactions among people, for learning within a specific context. Besides that, the literature also reveals that MARGS can have an impact on the development of competencies, such as scientific argumentation or collaboration [12]. Additionally, the authors of [13] mentioned that, for students to develop essential 21st century skills, such as problem solving, collaboration, and digital and communication proficiency, more active 
and authentic learning methods are needed, both inside and outside the classroom. The development of those competences requires learners to take the responsibility for their learning and become engaged participants, rather than passive observers [14].

The supporting technologies for the implementation of this type of teaching and learning approach are increasingly pervasive and popular [15], so it is time for MARGs adoption in educational contexts. However, new practices require teacher training, as teachers are often reluctant to integrate innovations into curriculum $[7,16]$. Additionally, as this is a relatively new field, there is a scarcity of educational resources articulated with the curriculum requirements, particularly in Portuguese language.

Considering the above, an accredited $50 \mathrm{~h}$ workshop was conducted to promote the collaborative development of MARGs for science, technology, engineering, and mathematics (STEM) learning, in which the authors of this study were trainers. The idea was to foster collaborative dynamics among educational researchers (trainers) and in-service teachers (trainees) for the design, construction, and implementation of high-quality science education resources, which could be integrated into games available for all.

The workshop was developed to foster authentic [17] and situated learning [18], whenever relevant outside the classroom, under the umbrella of constructivist learning [19]. The participant teachers assume an active role by constructing new knowledge within the articulation between the learning experience and previous knowledge, in collaboration with other colleagues of different subject areas, in an interdisciplinary approach.

The assumption is that this approach can increase teachers' motivation for the adoption of MARGs in their practices. The quality and relevance of the produced resources were supported by the integration of recommendations from the literature on effective teaching and learning methodologies, particularly when seeking to take advantage of the potential of technologies.

The workshop explored an already existing open educational app that supports MARGs, the EduPARK app (http://edupark.web.ua.pt/mobile_app, accessed on 26 September 2021), available both in English and Portuguese. This app integrates AR contents, games, and outdoor environments to promote cross-subjects as well as contextualized and authentic learning. It has displayed a high usability and educational value in several educational contexts [2]. The underlying principles of its creation are as follows: (i) to stimulate the app users to become active participants in their own learning, in a user-centered learning process with hands-on activities; (ii) to foster collaboration among app users from the same work group, through debate of ideas before answering questions, instead of making use of only competitive approaches; (iii) to embed learning in a real context, a park, which is rich in biology, history, and mathematics learning opportunities, thus providing authentic and situated learning experiences; (iv) to offer multiple modes of representation, namely through AR contents with video, audio, text, and 3D models; (v) to allow users to progress at their own pace, not establishing limited time to answer the challenges posed through the app; and (vi) to provide feedback with a scientific explanation after answering the proposed challenges. All of these features are fully explained in [2].

The aim of this study is to propose a set of guidelines for STEM teacher training on MARGs, emergent from the perspectives of the teacher trainees who participated in the above presented workshop, at the end of the training process. The following sections briefly present and discuss (a) the methodology adopted in this qualitative documental analysis study, including the description of the teacher training workshop and the data gathering and analysis procedures; (b) the results and discussion concerning the participant teachers' perspectives on the professional development process promoted by the workshop; and (c) guidelines for STEM teacher training in MARGs, as well as limitations and recommendations for future work.

\section{Methods}

The research reported in this work is framed in the Interpretivist Paradigm, which is focused on understanding the subjective world of human experience [20]. In this study, 
the purpose is to understand the experience of STEM teachers in a $50 \mathrm{~h}$ workshop aiming to promote the collaborative development of open digital educational resources based on teaching approaches integrating MARGs. Hence, it is classified as a descriptive qualitative study, one of the most common research designs in the field of Education [21], and it is guided by the following research question: How was the training process of this workshop, which targets MARGs' integration into teacher practices, according to the teacher trainees? The literature indicates that questions starting with "how" are useful in presenting a picture of types of social activities in descriptive studies [22].

To uncover the meaning of the MARGs workshop for the trainees, documental analysis of their individual reflective reports was conducted. These documents give researchers access to teachers' views on the training process, and thus allow hearing their voices on this matter. Whereas document analysis has served mostly as a complement to other research methods, it has also been used as a stand-alone method in qualitative studies, thanks to its unobtrusive and nonreactive qualities [23].

The context of qualitative studies is of most relevance, as contextual data are required for other researchers and practitioners to be able to relate the study findings to their own contexts [20]. Considering this need, Section 2.1 offers a detailed description of the workshop for in-service teachers.

For characterization of the 14 study participants (presented in Section 2.2), data from a questionnaire filled in by teacher trainees were submitted to descriptive analysis. The involvement of a small number of participants in qualitative studies is frequent [21], as this option allows to uncover key aspects of the study more clearly [22]. Moreover, as in [24], the aim of this study is not to make claims about STEM teachers and MARGs' integration into their practices, in general, as no statistical generalization is intended. Instead of that, the purpose is to have access to the experiences of STEM teachers when confronted with new teaching strategies, in order to disclose empirical data useful to propose a set of guidelines for MARGs' integration into practices.

\subsection{The Context: Teacher Training Workshop in Mobile AR Games}

The workshop explored the EduPARK app (http:/ / edupark.web.ua.pt/mobile_app, accessed on 26 September 2021) created under the EduPARK project, funded by FEDER and FCT (2016-19). The project is still running and seeks to promote cross-subjects' learning in outdoor environments supported by mobile devices, AR technology, and game-based learning under geocaching principles. The EduPARK app gives access to educational guides (Figure 1), each one corresponding to a game, to be explored in the Aveiro green park, in Portugal. The app has revealed a high usability and educational value in several educational contexts, from basic to higher education contexts, as well as in non-formal and informal educational contexts. This approach allows learning to move from the classroom to natural spaces, through an outdoor game in a treasure hunt format and by adding AR to an everyday technology - the smartphone. Exploring a green park provides an example of a truly authentic context for situated and contextualized learning, where the location is essential for learning. The app can be explored either individually or in a group, although working in groups may support the users' construction of meaning, with this being influenced by the interaction of the learners' prior knowledge with the new experiences, as well as by their interactions with others [2]. 

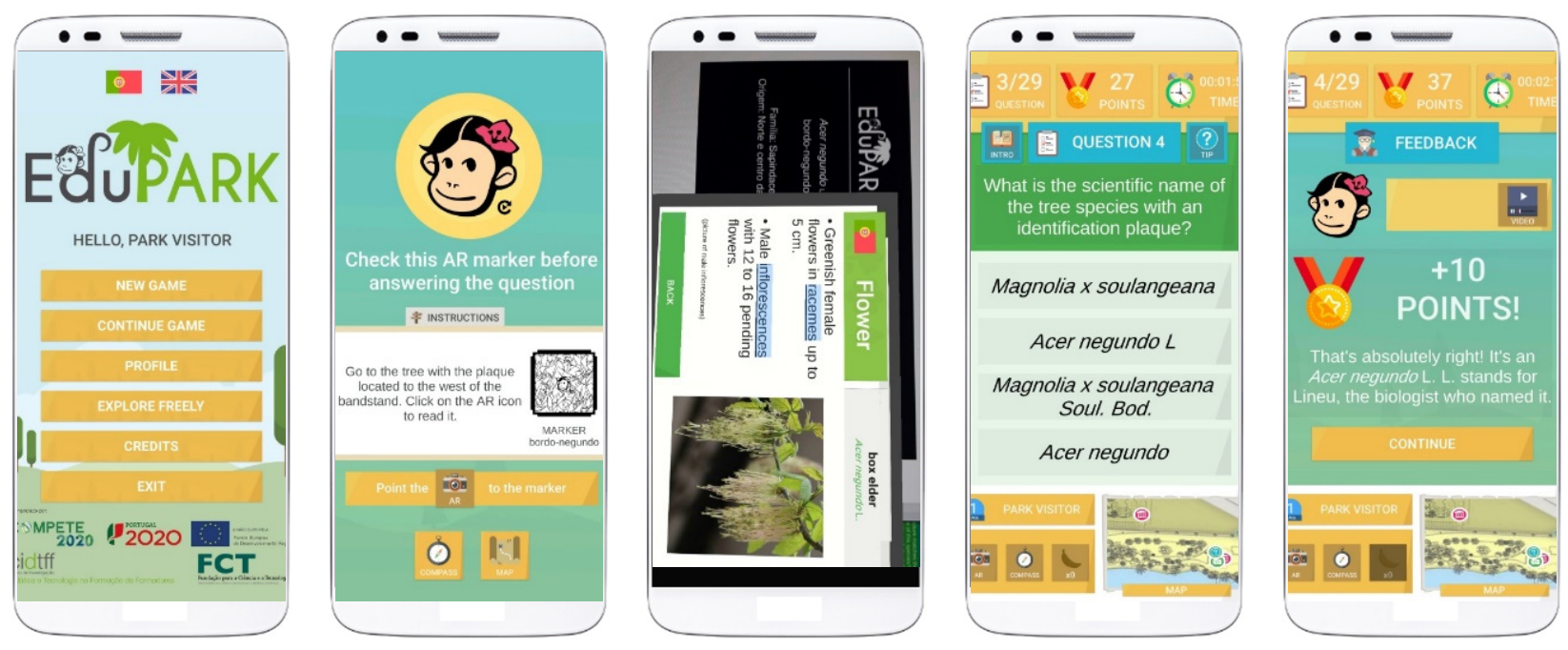

Figure 1. Selected screens of the EduPARK app and game.

The EduPARK project has developed several short-term training actions to promote teacher adoption of these innovative and effective approaches. However, the integration of technologies into educational practices requires longer training, prompting teachers to create content and games, and not just use them with students. Consequently, a $50 \mathrm{~h}$ workshop ( $25 \mathrm{~h}$ in face-to-face sessions and $25 \mathrm{~h}$ of autonomous work) was conducted between October 2020 and January 2021. It was certified as accredited training for inservice teachers, with an impact on career progression. The workshop trainers have several years of experience as science education researchers, particularly in MARGs field. The workshop aimed to create opportunities for teachers and researchers to collaborate in the development of high-quality open MARGs for STEM learning, accessed through the EduPARK app. The quality and relevance of the resources were supported by the integration of recommendations from the literature on effective teaching and learning methodologies, particularly when seeking to take advantage of technologies' potential. The produced resources are articulated with the National Science Curriculum and grounded in real educational contexts.

The workshop involved the following activities:

- Filling in of an initial adaptive online questionnaire with a mixture of closed-ended and open-ended questions for participants' initial characterization;

- Discussion and reflection on the theoretical framework, particularly in what concerns mobile learning, AR in education, and game-based learning;

- Exploring a MARG, selected by teacher trainees from those already available in the EduPARK app, as if teachers were students, in Aveiro green park;

- Collaborative design and development of educational resources that may be integrated as a MARG in the EduPARK app;

- Presentation and discussion of the resources to introduce improvements and create a MARG aggregating the best resources produced;

- Testing of the MARG in the Aveiro green park;

- Improvement of the MARG, considering issues uncovered during testing in loco.

\subsection{Study Participants}

The initial questionnaire allowed participants' characterization in what concerns the following: (a) motivations to attend the workshop and expectations; (b) conditions for the use of digital technologies in the teacher's educational context; (c) basic knowledge, previous experience and frequency of use, and perceptions about advantages and disadvantages on the workshop topics-mobile learning, AR use in Education, and game-based learning; and (d) demographic data, collected anonymously, such as gender, academic qualifications, 
and years of teaching experience. The analysis of the results of this questionnaire is presented in the work of [25], so here, only the main information needed to understand this study's results is presented.

From the 16 teachers attending the workshop, 14 gave informed consent to participate in this study. The workshop's teacher cohort profile matches closely the Portuguese teacher profile according to PORDATA (https://www.pordata.pt/, accessed on 26 September 2021) in terms of the following: (a) gender, as 12 females and 2 males participated in the study; and (b) experience, as 12 teachers had more than 21 years of experience. Their academic qualifications were as follows: (a) high degree (10 teachers), which is mandatory by Portuguese Law; (b) post-graduation course (1 teacher); and (c) Master's degree (3 teachers). The subjects taught were the following: (a) mathematics in the third cycle of basic education (CBE) or in secondary teaching (ST) (3 teachers); (b) physics and chemistry in the third CBE or in ST (6 teachers); (c) nature sciences in the third CBE (1 teacher); and (d) mathematics and nature sciences in the second CBE (years 5 and 6) (6 teachers) [25]. In Portugal, the first CBE corresponds to schoolyears 1 to 4 , attended by children from 6 to 10 years old; the second CBE corresponds to schoolyears 5 and 6 , attended by children 11 and 12 years old; and the third CBE corresponds to schoolyears 7 to 9 , attended by children from 13 to 15 years old. ST corresponds to schoolyears 10 to 12 , attended by teenagers from 16 to 18 years old. This school level is included in the compulsory schooling.

Teachers described different technology conditions in their schools, which influence MARGs' integration into teaching practices. Yet, several reported outdated devices and unreliable Internet connection in their schools. Moreover, their students had low levels of access to technology provided by the school, so the implementation of the workshop strategies required a bring your own device (BYOD) approach (idem).

Regarding the workshop topics, not surprisingly, most teachers did not know AR, and none had previous experience with it, neither as a user nor in their teaching practices. They acknowledge being unaware of AR technologies and of their potential use in education. In the case of this specific emerging technology, it is of primordial relevance to provide opportunities for teachers to experience learning with $\mathrm{AR}$ and to allow them to explore possibilities in terms of the teaching and learning processes (ibidem).

As to the other workshop topics, most teachers revealed naïve or imprecise perspectives. Their previous experience with mobile and game-based learning varied from those who did not know and did not use to those who seem to have somewhat accurate ideas and even some teaching experience. However, most teachers seemed to have a negative perspective towards the use of mobile devices in their practices, as the majority indicated more constraints than advantages on this approach. As to game-based learning and AR, teachers seemed to have a neutral opinion, as they mentioned the same number of advantages and barriers. Teachers acknowledged in these strategies a high potential to promote students motivation to learn and, consequently, to promote effective learning, sometimes in a fun way. However, teachers highlighted that all needed to have access to resources, such as the devices themselves and good quality Internet connection. In the case of games, it is important to know which educational resources can be implemented. Another constraint in the mind of almost half of respondents is students' distraction (ibidem).

\subsection{Data Gathering and Analysis}

Document analysis is a systematic procedure for reviewing documents to elicit meaning, gain understanding, and develop empirical knowledge [26]. The analytic procedure entails finding, selecting, appraising (making sense of), and synthesizing data, as excepts, quotations or entire passages, to be organized into major themes, categories, and case examples [27].

Documents analyzed in this study are the participating teachers' final reflections on the workshop process. These reflections (14) were made autonomously and individually right after the workshop activities, and they were one of the assessment elements for teachers' credits (counting 20\%). To analyze the reflections, categories were defined according to the 
topics suggested to teacher trainees, as follows: (i) reflexive analysis on the training process and (ii) achieved learning and its applicability in teaching practice. The first category is divided into five subcategories, related to the training activities: (a) theoretical framework on the workshop' topics; (b) group reflection; (c) exploration of an EduPARK game; (d) creation of questions for integration in a MARG; and (e) collaborative work. The results of reflections' analysis are shown and discussed in the next section.

All data collection, processing, and storage procedures respected research ethics principles. Informed consent from participants was requested, assuring no risk, harm, or disadvantages for the trainers, regardless of their decision on acceptance to participate in the study. Moreover, collected data were anonymized in order to not include any personal information or set of information allowing the identification of specific participants.

\section{Results and Discussion}

According to the collected data, this STEM teacher training workshop answered teachers' personal and professional needs regarding the reflection on teaching practices and the development of skills that facilitate the use of innovative and cross-subject resources integrated into STEAM-related curriculum.

Table 1 articulates the categories and subcategories of teachers' reflections with illustrative citations, from which the guidelines have emerged, providing an overall view of the results.

Concerning the (i) Reflexive analysis on the training process, overall, teachers stated that the workshop immediately awakened their interest, as they thought it could be an opportunity to improve their practices and knowledge in the area of using digital resources and mobile devices in classes, as they are part of the daily experiences of all (teachers and students). Teachers emphasized that they aimed to innovate and improve their practices, as a way to motivate and encourage students, promoting learning and encouraging in them a taste for studying.

Table 1. Categories and subcategories of analysis, citation examples from teachers' reflections, and guidelines that emerged from the data.

Category Subcategory Citation Example(s)

(a) Theoretical framework on the

(i) Reflexive analysis on the training

process workshop' topics;
"The theoretical framework work allowed me to know what augmented reality (AR) is." T6 ${ }^{1}$

"I learned to create virtual boards to organize work, studies or personal projects in Padlet" T1

"This task was enriching as it allowed for collaboration and mutual support among the teachers of the group in acquiring and deepening knowledge, always aiming at the common goal." T4
(1) Lay the training's foundations by initiating it with activities focusing on the theoretical framework, especially if it has elements completely new for teachers, such as AR;

(2) Along with the theoretical exploration, use practical tools that allow teachers to be active and present their ideas, as Padlet or Mentimeter;

(3) Propose autonomous group reflection on the theoretical framework, to allow deepening teachers' knowledge through discussion with peers; 
Table 1. Cont.

\begin{tabular}{|c|c|c|c|}
\hline Category & Subcategory & Citation Example(s) & Guideline(s) \\
\hline & $\begin{array}{l}\text { (d) Creation of } \\
\text { questions for } \\
\text { integration in a MARG; }\end{array}$ & $\begin{array}{l}\text { "It was important to try out } \\
\text { the EduPARK app at the park, } \\
\text { as it allowed us to live the } \\
\text { educational experience that is } \\
\text { intended for students." T9 } \\
\text { "I think the second visit to } \\
\text { Parque Infante D. Pedro was } \\
\text { extremely fruitful, as we had } \\
\text { the opportunity to test the } \\
\text { game created by all the } \\
\text { trainees, aiming its } \\
\text { improvement." T8 } \\
\text { "Creating questions for an } \\
\text { EduPARK game was } \\
\text { undoubtedly a great challenge, } \\
\text { but, at the same time, one of } \\
\text { the most exciting and } \\
\text { enriching aspects of this } \\
\text { training workshop." T8 } \\
\text { "The collaborative work with } \\
\text { colleagues from other areas, } \\
\text { namely Mathematics, allowed } \\
\text { to know new effective } \\
\text { methodologies through the } \\
\text { debate of ideas and } \\
\text { experiences." T6 } \\
\text { "The analysis of the created } \\
\text { questions by other classmates } \\
\text { [outside the teachers' own } \\
\text { group] and the trainers } \\
\text { themselves was very } \\
\text { productive, as suggestions for } \\
\text { improvement were given by } \\
\text { trainees." (T8) } \\
\text { people with a slightly different } \\
\text { background and with different } \\
\text { points of view." (T5) } \\
\text { "Also noteworthy is the role of } \\
\text { learned a lot. They were } \\
\text { tirainers in their support,... } \\
\text { pome relationship with the } \\
\text { thishing a very }\end{array}$ & $\begin{array}{l}\text { (7) Promote collaborative work } \\
\text { with colleagues from other } \\
\text { subject areas, to enhance the } \\
\text { creation of cross-subject } \\
\text { resources; } \\
\text { (8) Allow the presentation and } \\
\text { discussion with the whole } \\
\text { group of the produced } \\
\text { educational resources, in order } \\
\text { to improve them and to } \\
\text { guarantee the highest quality; } \\
\text { (9) Promote a good relationship } \\
\text { among all participants } \\
\text { (including trainees and trainers), } \\
\text { which is fundamental to } \\
\text { develop a safe and encouraging } \\
\text { environment for debating ideas, } \\
\text { open negotiation, and } \\
\text { knowledge sharing; }\end{array}$ \\
\hline $\begin{array}{l}\text { (ii) Achieved learning } \\
\text { and its applicability in } \\
\text { teaching practice }\end{array}$ & $\mathrm{N} / \mathrm{A}$ & $\begin{array}{l}\text { "The balance I make of this } \\
\text { training for my personal and } \\
\text { professional development is } \\
\text { extremely positive, as it } \\
\text { allowed me to review and } \\
\text { update my traditional } \\
\text { teaching methods and open } \\
\text { the doors to new practices." T8 }\end{array}$ & $\begin{array}{l}\text { (10) Explore teaching } \\
\text { approaches, tools, and resources } \\
\text { with relevance and applicability } \\
\text { in STEM teachers' classes, } \\
\text { supporting changes in their } \\
\text { practices and being valued by } \\
\text { teachers. }\end{array}$ \\
\hline
\end{tabular}

${ }^{1} \mathrm{~T}$ (number) indicates the number of the participant teacher, for anonymity purposes. 
Teachers also mentioned that the activities developed during the training workshop were very interesting because they contributed to the development of competences and attitudes required to become better teachers. Teacher 9 stated, "The training project provided me with action strategies that allow me to become a teacher that is more intervening, critical, supportive and entrepreneurial in the exploration of new pedagogical resources". Another teacher pointed out, "As a teacher, I believe that this educational strategy (app game) has potential impact on society, considering the use of innovative practices that brings the tools of the new age to schools" (T1).

Teachers also referred the advantage of using new digital tools in the workshop, such as Padlet and Mentimeter, as they plan to use them in their teaching practice. They overall revealed positive feelings about the workshop, stating that the proposed activities were so motivating that they were impregnated with an immense desire to develop them in an environment of immense joy and satisfaction.

The (ia) Theoretical framework on the topics covered in the workshop, in the opinion of teachers, was adequate and allowed them to know the educational potential of mobile devices, AR, gaming and outdoor environments. Hence, they considered that they evolved from the naïve perspectives and incipient (or lack of) experience identified at the beginning of the workshop [25] to more knowledgeable states. The main progression teachers referred to was related to AR. They mentioned the workshop was an opportunity for them to know more about this technology and recognized its potential for learning. For example, a teacher mentioned, "AR is a technology with great applicability in Science Education, providing different means to facilitate the understanding of concepts with the help of 3D models, in which students have the opportunity to directly observe, allowing them to apply scientific knowledge to their daily lives" (T1). Thus, this study reinforces the previous one that pointed that it is of primordial relevance to provide opportunities for teachers to experience learning with $\mathrm{AR}$ and to allow them to explore possibilities in terms of the teaching and learning processes [25].

Concerning the other two main topics, teachers say they are starting to integrate outdoor mobile and game-based learning in their practices. A teacher states, "In my practice, I often use outdoor resources and games, as students get more motivated and, thus, achieve better school results. Game-based learning generates competition between groups, leading to students' enthusiastic commitment and learning, while having fun. Students do not forget these lessons anymore" (T1). It is also widely agreed that there is not a unique effective teaching methodology, but a set of methodologies that, articulated with each other, may have a positive impact in terms of students' learning. "The way teacher guides the classes is very important" was stated by Teacher 8, and "It is crucial to keep students motivated resorting to strategies that avoid their demotivation" (T12) is also a global concern. Globally, teachers recognized the value of MARGs' integration in teacher practices as they promote students' involvement for deeper learning, which is in accordance with the literature [2-4].

Considering the results presented above, guidelines (1) and (2) emerged (Table 1). They highlight the relevance of the theoretical background for teacher training, especially regarding new topics or emergent technology. However, it is also of importance that teachers have opportunities to actively get involved in the learning of the foundational ideas, and share their thoughts on them. Hence, digital tools such as the Mentimeter or Padlet can be leveraged to share teachers' voices.

The (ib) Group reflection task was considered very important to understand the potential of mobile devices, AR, gaming, and outdoor environment, as it helped to clarify the concepts. This was also useful because it allowed teachers to reflect on the potential and difficulties of using these strategies in their practices. The fact that it was carried out in groups supported peer interaction: "It allowed the creation of bonds and willingness to work in the near future, based on the sharing, cooperation and collaboration among us" (T6). From these results, guideline (3) was unveiled, which focuses on peer discussion among teachers, deepening the theoretical framework. 
Concerning the task (ic) Exploration of an EduPARK game, the teachers widely agreed; "One of the highlights of this workshop was undoubtedly, the experimentation of the EduPARK app as if the trainee teachers were students" (T4). Teachers also considered that it was important to try out the EduPARK app in the park, as it allowed to live the educational experience that it is intended to be explored with students. A teacher stated, "It was possible to perceive the motivation caused by playing the game on mobile devices, with scores and competition among groups" (T5). Another pointed out that, "It was also possible to verify the potential of AR in loco and to experiment the sensation that our students will live" (T8). The results gave origin to guidelines (4) and (5), highlighting the need for teachers assuming the role of students inclusively, while testing in loco the educative resources they had created, to be able to acknowledge the educative potential and constraints of the new teaching approaches and resources.

Producing a new game through the (id) Creation of questions to integrate in the EduPARK app was considered by all teachers to be a big challenge, but at the same time, one of the most exciting and enriching aspects of this training workshop: "This task was very motivating and the most challenging, as it went through the design, elaboration and production of Science Education resources integrated in the EduPARK app" (T8); "I enjoyed the experience so much that I had a lot of ideas. The same happened to my colleagues, in such a way that we did more questions than the ones we were asked for" (T5). Teachers also mentioned that the process of presenting the questions and the debate of ideas among trainees and trainers was also constructive and enthusiastic, contributing to the improvement of the produced work and the enrichment of all involved in these processes. From this result, guideline (6) emerged, regarding the relevance of creating new open resources by teachers in training, for sharing of best practices.

The (ie) Collaborative work, both within work groups and in the big group, was also mentioned as a very favorable aspect, specifically in the task of creation of questions, as this approach allowed teachers to share knowledge with other colleagues of different STEM curricular areas, improving cross-subjects and transdisciplinary contents in the resources. In these, content and knowledge are not isolated, but intersect and complement each other in real life. In addition, it was pointed out that, "the exchange of experiences was enriching, as it allowed us to obtain written support with new and creative ideas and to improve others' work, enabling arguments to expand our practices" (T2). Teacher 2 also mentioned, "The exploration of resources through 'learning by doing' in groups was very motivating and challenging thanks to the mutual support promoting collaboration between all". The positive relationship among participants was frequently mentioned, both among trainees and with the trainers, which is crucial for a teacher to feel confident in sharing ideas and experiences. From these results, three guidelines were revealed: (7) to (9). These focus on the relevance of shared work among groups members, which is richer if conducted by teachers from different STEAM subject areas, as well as between different groups and trainers, in a secure environment. Lastly, considering the (ii) Achieved learning and its applicability in teaching practice, this training workshop seemed to have a huge impact on the teachers' perceptions about mobile AR learning, game-based, and outdoor learning, as it allowed an increased awareness of these concepts and their applicability in teaching practice. Teacher 4 stated, "The presented contents, the carried-out activities, the produced materials and the sharing will not only contribute to improve my pedagogical practices, but it will also achieve important results in terms of innovation in Science Education practices. This has impact in students learning, in what concerns, namely, behavior changes towards environmental conservation and healthy lifestyles". It was also highlighted that, "this training was important and contributed to my motivation to change educational practices, aiming improving the quality of teaching" (T2). Concerning teachers' will to use the app with their students, one teacher stated, "I have the privilege of teaching at a school near Infante D. Pedro Park, so I'm able to use the EduPARK app in the outdoors" (T9). Another two teachers stated that, within the domains of curricular autonomy, which promotes student-centered practices, they had suggested the development of the project "Learning 
in the City Park" and presented the idea to other colleagues of their school. The project involves more subjects in the exploration of the potential of the EduPARK app. This idea aroused curiosity among the teachers' colleagues, so they tested the app in the park, and then they applied it with their students. This type of dissemination of innovative teaching approaches to teachers' school colleagues has been reported in the literature before, such as the case of [28]. This study presents evidence supporting the claim that innovation created in collaboration between researchers and teachers may be more easily adopted by teachers and can have an impact on their colleagues' practices as well.

In summary, most of teachers acknowledged the importance of this training workshop for their personal and professional development, as it enabled them to review and update their traditional teaching methods and try new ones. For example, they showed interest and intention to explore the AR app with their students, not just inside, but also outside school. From these results, guideline 10 emerged, the last one proposed in this work, reinforcing that it is important to approach topics and methods that can be applied by teachers in their own schools, with an impact on their teaching practices. Additionally, when trainee teachers perceive these innovations as beneficial, they act as ambassadors, attributing to these training initiatives a potential impact on their school colleagues' practices.

\section{Guidelines for STEM Teacher Training in Mobile Augmented Reality Games}

With the aim of proposing guidelines for STEM teacher training in MARGs, this paper presents a qualitative study with three of the characteristics Merriam and Tydel [21] identify in qualitative research, as follows: (1) the focus is on understanding phenomena, in this case, the teachers' views of the training process; (2) the researchers are the primary instruments of data collection and analysis, in this case, through documental analysis of teachers' reflection reports at the end of the training; and (3) the product is richly descriptive, conveying what the researchers have learned from the study, relying on quotes from the teachers' reports to support the study findings.

Starting from the results concerning teachers' reflections, a set of guidelines (as presented in Table 1) are put forward to be useful for those who intend to conceive and develop training workshops for continuous professional development of STEM teachers aiming MARGs' integration into teacher practices, as follows:

(1) Lay the training's foundations by initiating it with activities focusing on the theoretical framework, especially if it has elements completely new for teachers, such as AR;

(2) Along with the theoretical exploration, use practical tools that allow teachers to be active and present their ideas, such as Padlet or Mentimeter;

(3) Propose autonomous group reflection on the theoretical framework, to allow deepening teachers' knowledge through discussion with peers;

(4) Organize activities where teachers assume the role of students, to allow them to recognize the potential of the proposed activities, as well as its constraints;

(5) Give opportunity for teachers to play the game created during the training, in loco, as this supports improvement, and it is definitely considered an asset by the teachers;

(6) Create and share educational resources (in this case, a MARG created) to be freely available for the world, as this has high potential to be very encouraging for teachers;

(7) Promote collaborative work with colleagues from other subject areas, to enhance the creation of cross-subject resources;

(8) Allow the presentation and discussion with the whole group of the produced educational resources, in order to improve them and to guarantee the highest quality;

(9) Promote a good relationship among all participants (including trainees and trainers), which is fundamental to develop a safe and encouraging environment for debating ideas, open negotiation, and knowledge sharing;

(10) Explore teaching approaches, tools, and resources with relevance and applicability in STEM teachers' classes, supporting changes in their practices and being valued by teachers. 
Considering all the above, the relevance of this research is to contribute to the success of future STEM teacher training initiatives aiming at enhancing the use of MARG in schools, being useful for both researchers and practitioners. The EduPARK app can be a good starting point to promote mobile AR game-based learning, as this resource is open, free of charge, and easy to use by teachers and their students. It is also available in Portuguese, which is the teacher participants' native language.

Further studies are needed with bigger and more diverse samples to better understand STEM teachers' opinions on exploring MARG in schools. Hence, future research should collect data with broader samples, namely teachers of non-STEM subjects, and should also involve an analysis of teachers' practices, to triangulate teachers' opinions with their effective practices. As only STEM teachers participated in this study, further studies are required to analyze if the guidelines proposed in this work are applicable in other areas outside STEM subjects.

Author Contributions: Conceptualization, L.P. and M.M.M.; Data curation, L.P. and M.M.M.; Formal analysis, L.P.; Investigation, L.P. and M.M.M.; Methodology, L.P. and M.M.M.; Project administration, L.P.; Writing—original draft, L.P. and M.M.M.; Writing—review \& editing, L.P. and M.M.M. All authors have read and agreed to the published version of the manuscript.

Funding: This research was funded by FEDER-Fundo Europeu de Desevolvimento Regional funds through the COMPETE 2020-Operational Programme for Competitiveness and Internationalisation (POCI), and by Portuguese funds through FCT-Fundação para a Ciência e a Tecnologia, grant number PO-CI-01-0145-FEDER-016542, and the work of the second author is funded by national funds (OE), through University of Aveiro, in the scope of the framework contract foreseen in the numbers 4, 5 and 6 of the article 23, of the Decree-Law 57/2016, of August 29, changed by Law 57/2017, of July 19 .

Institutional Review Board Statement: Ethical review and approval were waived for this study, due to being a study involving a small number of healthy adults, participating under informed consent, and with no sensitive data collection.

Informed Consent Statement: Written informed consent was obtained from all subjects involved in the study.

Data Availability Statement: The data presented in this study are available on request from the corresponding author. The data are not publicly available due to privacy issues.

Acknowledgments: The authors thank the participating teachers for accepting taking part of this study. The authors also thank the reviewers for their insightful comments.

Conflicts of Interest: The authors declare no conflict of interest. The funders had no role in the design of the study; in the collection, analyses, or interpretation of data; in the writing of the manuscript; or in the decision to publish the results.

\section{References}

1. Laine, T. Mobile Educational Augmented Reality Games: A Systematic Literature Review and Two Case Studies. Computers 2018, 7, 19. [CrossRef]

2. Pombo, L.; Marques, M.M. The potential educational value of mobile augmented reality games: The case of edupark app. Educ. Sci. 2020, 10, 287. [CrossRef]

3. Costa, M.C.; Manso, A.; Patrício, J. Design of a Mobile Augmented Reality Platform with Game-Based Learning Purposes. Information 2020, 11, 127. [CrossRef]

4. Ardito, C.; Buono, P.; Costabile, M.F.; Lanzilotti, R.; Pederson, T. Re-experiencing history in archaeological parks by playing a mobile augmented reality game. In Proceedings of the Lecture Notes in Computer Science (including subseries Lecture Notes in Artificial Intelligence and Lecture Notes in Bioinformatics); Meersman, R., Tari, Z., Herrero, P., Eds.; Springer: Vilamoura, Portugal, 2007; Volume 4805 LNCS, pp. 357-366.

5. Shu, L.; Liu, M. Student Engagement in Game-Based Learning: A Literature Review from 2008 to 2018. J. Educ. Multimed. Hypermedia 2019, 28, 193-215.

6. Fotaris, P.; Pellas, N.; Kazanidis, I.; Smith, P. A systematic review of Augmented Reality game-based applications in primary education. In Proceedings of the 11th European Conference on Games Based Learning, ECGBL 2017, Graz, Austria, 5-6 October 2017; Joanneum, F., Ed.; University of Applied Sciences: Graz, Austria, 2017; pp. 181-190. 
7. Aivelo, T.; Uitto, A. Digital Gaming for Evolutionary Biology Learning: The Case Study of Parasite Race, an Augmented Reality Location-Based Game. LUMAT Int. J. Math Sci. Technol. Educ. 2016, 4, 1-26. [CrossRef]

8. Sungkur, R.K.; Panchoo, A.; Bhoyroo, N.K. Augmented reality, the future of contextual mobile learning. Interact. Technol. Smart Educ. 2016, 13, 123-146. [CrossRef]

9. Chang, G.; Morreale, P.; Medicherla, P. Applications of Augmented Reality Systems in Education. In Proceedings of the Society for Information Technology \& Teacher Education International Conference 2010, San Diego, CA, USA, 29 March-2 April 2010 ; Gibson, D., Dodge, B., Eds.; Associationn for the Advancement of Computing in Education: Chesapeake, VA, USA, 2010; pp. $1380-1385$.

10. FitzGerald, E.; Ferguson, R.; Adams, A.; Gaved, M.; Mor, Y.; Thomas, R. Augmented Reality and Mobile Learning: The State of the Art. Int. J. Mob. Blended Learn. 2013, 5, 43-58. [CrossRef]

11. Dunleavy, M.; Dede, C. Augmented Reality Teaching and Learning. In The Handbook of Research for Educational Communications and Technology; Spector, M., Merrill, M.D., Elen, J., Bishop, M.J., Eds.; Springer: New York, NY, USA, 2014; pp. 735-745, ISBN 978-1-4614-3184-8.

12. Koutromanos, G.; Sofos, A.; Avraamidou, L. The use of augmented reality games in education: A review of the literature. EMI Educ. Media Int. 2015, 52, 253-271. [CrossRef]

13. Johnson, L.; Becker, S.A.; Cummins, M.; Estrada, V.; Freeman, A.; Hall, C. The NMC Horizon Report: 2016 Higher Education Edition; The New Media Consortium: Austin, TX, USA, 2016.

14. Pombo, L.; Marques, M.M.; Afonso, L.; Dias, P.; Madeira, J. Evaluation of a mobile augmented reality game application as an outdoor learning tool. Int. J. Mob. Blended Learn. 2019, 11, 59-79. [CrossRef]

15. Mascheroni, G.; Cuman, A. Net Children Go Mobile: Final Report. Deliverables D6.4 E D5.2; Educatt: Milano, Italy, 2014.

16. Ertmer, P.A.; Ottenbreit-Leftwich, A.T. Teacher technology change: How knowledge, confidence, beliefs, and culture intersect. J. Res. Technol. Educ. 2010, 42, 255-284. [CrossRef]

17. Hill, A.M.; Smith, H.A. Research in purpose and value for the study of technology in secondary schools: A theory of authentic learning. Int. J. Technol. Des. Educ. 2005, 15, 19-32. [CrossRef]

18. Lave, J.; Wenger, E. Situated Learning: Legitimate Peripheral Participation; Cambridge University Press: Cambridge, UK, 1991; ISBN 9780521423748.

19. Burr, V. Social Constructionism; Routledge: London, UK, 2015.

20. Kivunja, C.; Kuyini, A.B. Understanding and Applying Research Paradigms in Educational Contexts. Int. J. High. Educ. 2017, 6, 26-41. [CrossRef]

21. Merriam, S.B.; Tisdell, E.J. Qualitative Research: A Guide to Design and Implementation; Jossey-Bass Higher and Adult Education Series, 4th ed.; Wiley: San Francisco, CA, USA, 2015; ISBN 9781119003618.

22. Neuman, W.L. Social Research Methods: Qualitative and Quantitative Approaches, 7th ed.; Pearson Education Limited: Harlow, UK, 2014.

23. Bowen, G.A. Document Analysis as a Qualitative Research Method. Qual. Res. J. 2009, 9, 27-40. [CrossRef]

24. DeMarrais, K.; Lapan, S.D. Foundations for Research: Methods of Inquiry in Education and the Social Sciences; DeMarrais, K., Lapan, S.D., Eds.; Lawrence Erlbaum Associates: Mahwah, NJ, USA, 2004; ISBN 0805836500.

25. Marques, M.M.; Pombo, L. Teachers' experiences and perceptions regarding mobile augmented reality games: A case study of a teacher training. In Proceedings of the INTED2021 Conference, Barcelona, Spain, 8-9 March 2021; Chova, L.G., Martínez, A.L., Torres, I.C., Eds.; IATED: Online, 2021; pp. 8938-8947.

26. Corbin, J.; Strauss, A. Basics of Qualitative Research: Techniques and Procedures for Developing Grounded Theory, 4th ed.; SAGE Publications: New York, NY, USA, 2014.

27. Labuschagne, A. Qualitative Research-Airy Fairy or Fundamental? Qual. Rep. 2015, 8, 100-103. [CrossRef]

28. Marques, M.M.; Loureiro, M.J.; Marques, L. Planning innovative teaching practices in a community of practice: A case study in the context of the project IPEC. Int. J. Web Based Communities 2011, 7, 429. [CrossRef] 